\title{
Hemorrhagic gastric ulcer after endoscopic ultrasound-guided fine needle aspiration of a pancreatic adenocarcinoma
}
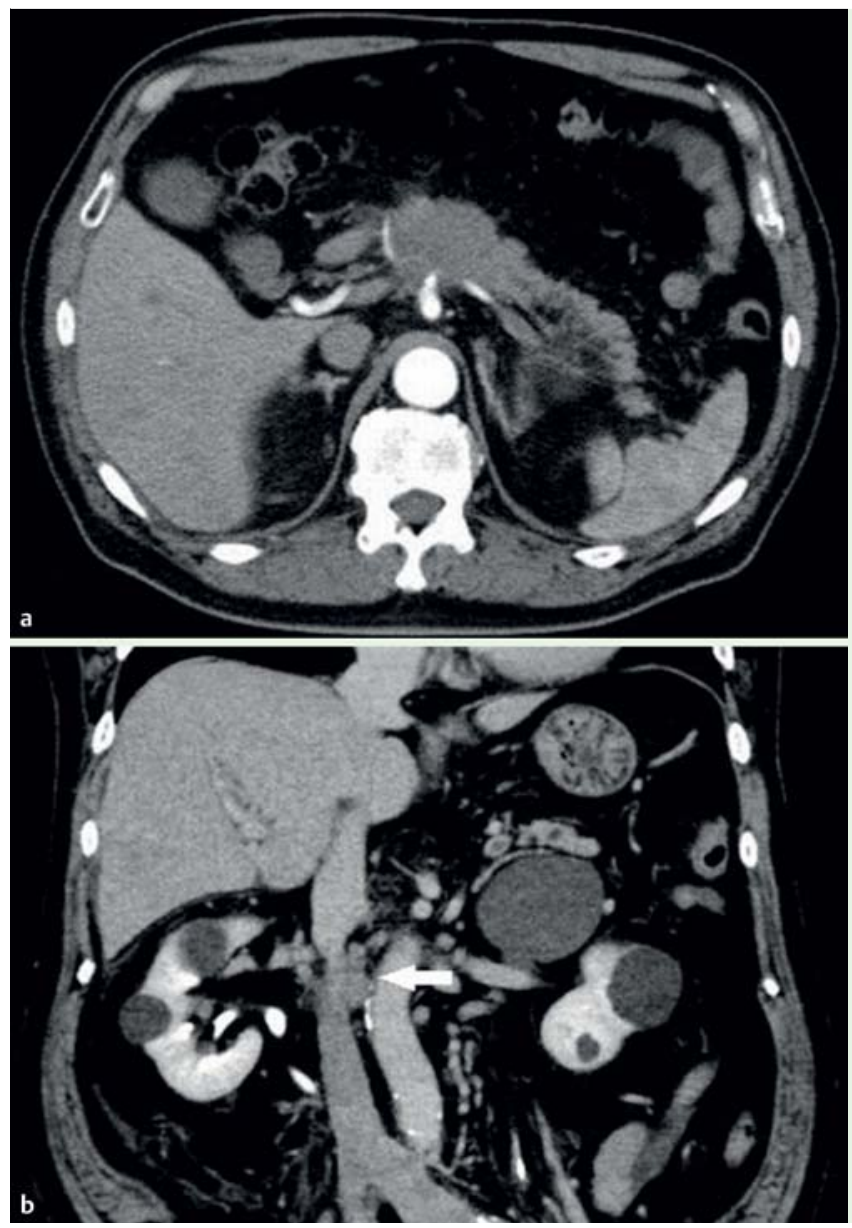

Fig. 1 Contrastenhanced computed tomography (CT) scan showing: a in early phase, a 3-cm hypovascular, irregular, tumorous lesion in the body of the pancreas, suspected of being pancreatic cancer, with invasion of the celiac, splenic, and common hepatic arteries; $\mathbf{b}$ in late phase, inferior vena cava invasion thought to be due to lymph node metastasis, and stenosis in the same area.
A 64-year-old man presented with a chief complaint of back pain. A contrast-enhanced computed tomography (CT) scan showed a 3-cm hypovascular, irregular, tumorous lesion in the body of the pancreas invading the celiac, splenic, and common hepatic arteries ( $\bullet$ Fig. 1 a). Inferior vena cava (IVC) invasion was thought to be due to lymph node metastasis ( Fig. $1 \mathbf{b}$ ), and thrombi in the peripheral veins were causing extensive blockage. An endoscopic ultrasound-guided fine needle aspiration (EUS-FNA) was performed (2 times, 10 strokes each) on the pancreatic lesion with a 22-gauge needle (Expect; Boston Scientific, Tokyo, Japan) ( $\bullet$ Fig.2). Pathological findings indicated invasive pancreatic ductal cancer. The patient was diagnosed with stage IVB cancer of the pancreatic body (Union for International Cancer Control classifica- tion). Systemic chemotherapy was planned, and edoxaban was administered for the venous thrombi caused by the IVC invasion.

On day 10 after the EUS-FNA, a small amount of hematemesis occurred. Upper gastrointestinal tract endoscopy showed a distinct ulcer, about $20 \mathrm{~mm}$ in size in the upper gastric body on the posterior wall of the greater curvature, on a background of atrophied gastric mucosa. Part of the ulcer was bleeding ( $\bullet$ Fig. 3). Coagulation hemostasis was performed with coagulation forceps (Coagrasper; Olympus Medical Systems). Subsequently, no further bleeding occurred. From the lesion's location, the changes were thought to have occurred after the EUS-FNA.

Bleeding due to EUS-FNA occurs $0.13 \%$ of the time [1], but there have been no reports of hemorrhagic gastric ulcers

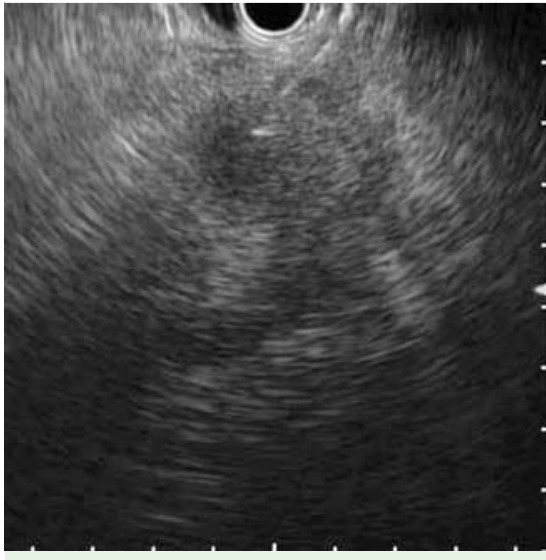

Fig.2 Image during endoscopic ultrasoundguided fine needle aspiration (EUS-FNA) showing a pancreatic lesion about $3 \mathrm{~cm}$ in size with an irregular margin and internal heterogeneity, consistent with pancreatic cancer.
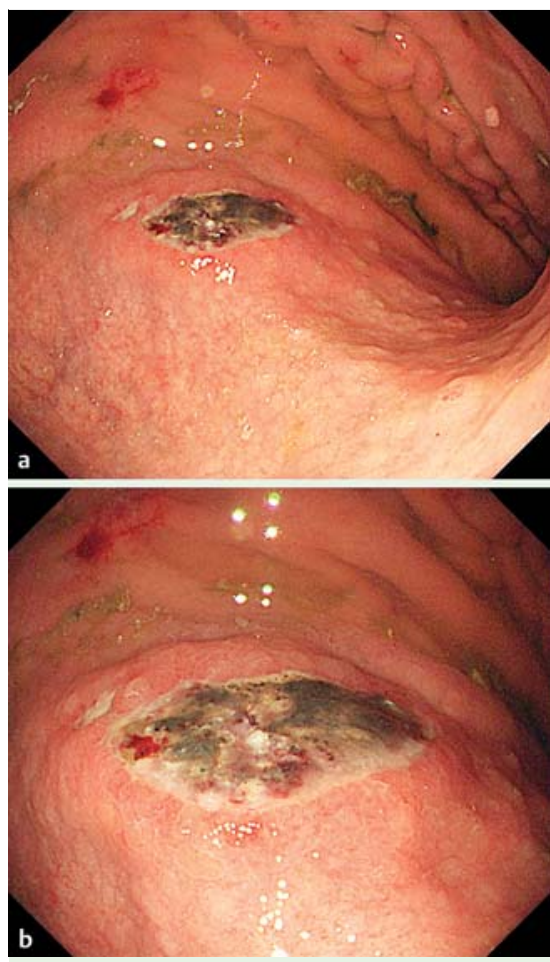

Fig. 3 Views during upper gastrointestinal tract endoscopy showing a distinct ulcer about $20 \mathrm{~mm}$ in size in the upper gastric body on the posterior wall of the greater curvature, with bleeding evident from the base of the ulcer, on a background of atrophied gastric mucosa. The patient's serum Helicobacter pylori antibodies were positive. 
caused by EUS-FNA, making the present case rare. The hemorrhagic gastric ulcer possibly occurred because the patient's serum tested positive for Helicobacter pylori antibodies and he was receiving ongoing edoxaban treatment. New oral anticoagulants, including edoxaban, have become widely used for atrial fibrillation and venous thrombosis [2,3]. A recent meta-analysis found a greater risk of gastrointestinal bleeding with edoxaban than with warfarin or other conventional therapies [4]. Therefore, care should be taken when performing EUS-FNA in patients who are receiving anticoagulants.

Endoscopy_UCTN_Code_CPL_1AL_2AB

Competing interests: None
Tomoya lida, Takeya Adachi,

Suguru Nakagaki, Takashi Yabana, Akira Goto, Yoshihiro Kondo

Department of Gastroenterology, Otaru

City General Hospital, Hokkaido, Japan

\section{References}

1 Wang KX, Ben QW, Jin ZD et al. Assessment of morbidity and mortality associated with EUS-guided FNA: a systematic review. Gastrointest Endosc 2011; 73: 283 -290

2 Giugliano RP, Ruff CT, Braunwald E et al. Edoxaban versus warfarin in patients with atrial fibrillation. NEJM 2013; 369: 2093 2104

3 Büller HR, Décousus H, Grosso MA et al. Edoxaban versus warfarin for the treatment of symptomatic venous thromboembolism. NEJM 2013; 369: 1406-1415

4 Loffredo L, Perri L, Violi F. Impact of new oral anticoagulants on gastrointestinal bleeding in atrial fibrillation: a meta-analysis of interventional trials. Dig Liver Dis 2015; 47: 429-431
Bibliography

Dol http://dx.doi.org/

10.1055/s-0034-1393586

Endoscopy 2015; 47: E635-E636

(c) Georg Thieme Verlag KG

Stuttgart · New York

ISSN 0013-726X

\section{Corresponding author}

\section{Tomoya lida, MD}

Department of Gastroenterology

Otaru City General Hospital

1-1 1-chome, Wakamatu-cho, Otaru

Hokkaido, 047-8550

Japan

Fax: $+81-134-326424$

tomoya.iida.0306@gmail.com 